\title{
EROSÃO EM ENTRESSULCOS SOB CAATINGA E CULTURAS AGRÍCOLAS ${ }^{(1)}$
}

\author{
Francisco José de Freitas ${ }^{(2)}$, José Ramon Barros Cantalice ${ }^{(3)}$, \\ Sandro Augusto Bezerra ${ }^{(4)}$, Maria Daniela Rodrigues de Oliveira \\ Silva ${ }^{(4)}$, Paulo Medeiros do Santos $^{(4)}$, Rossini Matos Correa ${ }^{(4)}$, \\ Priscila Alves Lima ${ }^{(4)}$ \& Sandro Barbosa Figueira ${ }^{(4)}$
}

\begin{abstract}
RESUMO
Dentre as formas de erosão hídrica do solo, a erosão em entressulcos é uma das que causam maiores danos no processo produtivo dos solos utilizados na agricultura, por provocar perdas de solo, água e nutrientes. Frente a isso, o presente trabalho visou avaliar a proteção ambiental promovida pela cobertura vegetal da caatinga, do feijão-guandu (Cajanus cajan) e da batata-doce (Ipomoea batatas Lam) em relação ao solo descoberto, bem como o efeito das práticas de cultivos dessas culturas, por meio das taxas da erosão em entressulcos e das características hidráulicas do escoamento superficial vinculado à erosão em entressulcos, em um Luvissolo. Para isso, foi implementada uma série de 20 chuvas simuladas em Serra Talhada, município do semi-árido do Estado de Pernambuco, sob os seguintes tratamentos: (1) solo descoberto; (2) solo coberto pela cultura do feijão-guandu (Cajanus cajan); (3) solo coberto pela cultura da batata-doce (Ipomoea batatas Lam.); (4) solo coberto por Caatinga semi-arbustiva. Todos os regimes de escoamento superficial obtidos foram laminar lento. As coberturas vegetais proporcionadas pela Caatinga e pelo guandu, que deram origem aos maiores valores de cobertura do solo, responderam pelas menores taxas de concentração de sedimentos e desagregação do solo na erosão em entressulcos, em decorrência da maior rugosidade hidráulica da superfície do solo promovida por essas vegetações. As taxas de concentração de sedimentos no cultivo da batata-doce foram iguais às do solo descoberto, por conta do revolvimento do solo na preparação das leiras de plantio, e determinou as maiores taxas de desagregação do solo entre as coberturas
\end{abstract}

(1) Parte da Dissertação de Mestrado do primeiro autor no Programa de Pós-Graduação em Ciência do Solo, Universidade Federal Rural de Pernambuco - UFRPE. Recebido para publicação em outubro de 2006 e aprovado em junho de 2008.

(2) Professor da Escola Agrotécnica Federal de Crato - EAFC. Rod. CE 292, Sítio Almécegas, Km 05, CEP 63100-000 Crato (CE). E-mail: franciscofreitasfj@@hotmail.com

${ }^{(3)}$ Professor Adjunto do Departamento de Agronomia, Universidade Federal Rural de Pernambuco - UFRPE. CEP 52171-900 Recife (PE). E-mail: cantalic@terra.com.br

(4) Pós-Graduando em Ciência do Solo, UFRPE.E-mails: sabezerra@hotmail.com; lelinharodrigues@yahoo.com.br ; santos.p.m@bol.com.br ; rossinimc@hotmail.com; priscilaea@hotmail.com; sandrofigueir@yahoo.com.br 
vegetais; em contrapartida, as leiras permitiram retenção do escoamento superficial. As coberturas vegetais Caatinga, guandu e batata-doce e as respectivas rugosidades hidráulicas impostas ao escoamento superficial determinaram reduções exponenciais das perdas de solo. A cobertura vegetal da Caatinga semiarbustiva proporcionou o menor coeficiente de escoamento superficial $(C=0,32)$, em decorrência de sua maior cobertura do solo, da maior resistência hidráulica e do não-revolvimento do solo.

Termos de indexação: ambiente semi-árido, rugosidade hidráulica, cobertura vegetal, impactos ambientais.

\title{
SUMMARY: INTERRILL EROSION UNDER SHRUB AND CROP SYSTEMS
}

\begin{abstract}
Among the different forms of water erosion, interrill erosion is one of the most deleterious to the productivity of soils used in agriculture, causing losses of soil, water and nutrients. This study sought to evaluate the efficiency of environmental protection by the Shrub cover types caatinga, Guandu (Cajanus cajan) and sweet potato (Ipomoea potatoes Lam) as compared to bare soil, as well as the effect of these crops on the interrill erosion and hydraulic properties of surface runoff in a Inceptisol. For this purpose, a series of 20 simulated rainfall events in Serra Talhada - PE, Brazil, semiarid area, on the following treatments: (1) bare soil; (2) soil covered with Guandu (Cajanus cajan); (3) soil covered with sweet potato (Ipomoea potatoes Lam.); (4) soil covered with caatinga (dry forest vegetation). All runoff flow regimes were laminar and slow. The lowest rates of sediment concentration and soil detachment in the interrills were observed for caatinga and Guandu covers, the species with the highest values of soil cover, due to the higher hydraulic soil surface roughness of these crops. The sediment concentration rates in sweet potato were equal to those of bare soil, due to soil revolving to prepare the planting furrows and the rates of soil detachment were the highest of all plant covers; on the other hand, the furrows retained surface runoff. Similarly, the plant covers caatinga, Guandu and sweet potato with the respective hydraulic roughness restricting runoff resulted in exponential reductions of soil losses. The runoff coefficient in the soil covered by caatinga vegetation was the lowest (0.2) due to the greatest soil cover, roughness and absence of soil tillage.
\end{abstract}

Index terms: semiarid environment, hydraulic roughness, soil cover, environmental impacts.

\section{INTRODUÇÃO}

A erosão em entressulcos pode ser vista como a combinação de dois diferentes processos: desagregação da massa do solo pelo impacto das gotas de chuva e pelo fluxo em entressulcos; e transporte do solo desagregado pelo escoamento em entressulcos, que parece não ter capacidade de transportar todo o sedimento produzido pelo impacto das gotas de chuva, com ou sem influência do impacto das gotas sobre o escoamento em entressulcos (Everaert, 1991). Assim, a erosão é um dos principais fatores responsáveis pelo decréscimo na produtividade agrícola, provocando perdas de solo, água e nutrientes, com conseqüente eutrofização dos corpos de água e degradação do solo (Lal, 1994; Hernani et al., 1999; Bezerra \& Cantalice, 2006).
Diversas são as formas de erosão hídrica do solo. A erosão em entressulcos é uma das formas mais danosas, pois remove a camada mais superficial do solo, onde se encontram a matéria orgânica, os nutrientes e os insumos agrícolas, que favorecem a produção agrícola, alterando também as condições para ocorrência dos processos microbianos que se refletem na fertilidade do solo, pela decomposição do material orgânico, disponibilizando os nutrientes para as plantas (Cantalice, 2002).

No Brasil, especialmente no Nordeste, a cultura do guandu (Cajanus cajan) foi introduzida, principalmente, devido à adaptação à seca e por crescer em solos pouco evoluídos, apresentando bons resultados como fornecedora de matéria verde de alta qualidade nos pastos em períodos de chuvas escassas, além de ser planta muito versátil, adaptada às condições 
climáticas do País, sendo utilizada também na rotação de culturas (Alves \& Medeiros, 1997). Por possuir essas características, a cultura do guandu ocupa mundialmente o sexto lugar em importância alimentar entre as leguminosas, sendo usada extensivamente na Ásia para a alimentação animal e humana. Para o produtor rural, o guandu proporciona baixo custo de produção e armazenamento de forragem no período da entressafra, que refletem diretamente no lucro da atividade pecuária e melhoria na fertilidade do solo, decorrentes da habilidade que essa forrageira apresenta para fixação simbiótica de $\mathrm{N}_{2}$ (Rao et al., 2002).

A batata-doce (Ipomoea batatas Lam.) é tida como cultura de vazante no Nordeste brasileiro, por ser tradicionalmente cultivada por pequenos produtores em pequenas áreas de vazante, utilizando-se quase sempre da mão-de-obra familiar, razão pela qual tem maior importância para populações de baixa renda (Silva, 1991). É uma cultura rústica, de fácil manutenção, com alguma resistência à seca e ampla adaptação, apresentando custo de produção relativamente baixo, com investimento mínimo, e de retorno elevado (Miranda et al., 1995), além de ser uma das hortaliças com maior capacidade de produzir energia por unidade de área e tempo (kcal ha $\left.{ }^{-1} \mathrm{dia}^{-1}\right)$. Para o plantio da batata-doce nas áreas de vazante, 0 solo é revolvido e preparado na forma de leiras transversais ao declive, proporcionando assim aumento no volume de água infiltrado no solo, com conseqüente diminuição do escoamento superficial e de sua ação erosiva, e melhor aproveitamento de água pela cultura

A capacidade da Caatinga de suportar os impactos provocados pela chuva e seu conseqüente escoamento superficial, na forma de erosão hídrica, é muito pouco conhecida. A Caatinga cobre uma grande área do semi-árido nordestino, e parte dela, correspondente a centenas de milhares de hectares, é derrubada anualmente para produção de lenha e para plantio no sistema de agricultura itinerante. Geralmente, nesses locais, após a retirada da madeira aproveitável, o material vegetal é queimado e o local abandonado ao crescimento da vegetação espontânea, no caso da produção de lenha, ou cultivado por alguns anos antes do abandono, no caso da agricultura itinerante. Em ambos os casos, é importante conhecer a capacidade de regeneração da vegetação nativa para o estabelecimento de um manejo sustentável em longo prazo. A população local tem conhecimento empírico do assunto, mas o conhecimento científico disponível é incipiente (Sampaio et al., 1998).

Avaliando no Nordeste brasileiro o efeito de diferentes coberturas do solo em área de cultivo de cana-de-açúcar sob o escoamento superficial na erosão em entressulcos nas condições de solo descoberto, com resíduo em contato direto com o solo, no dossel da canade-açúcar, bem como o efeito somado do dossel da canade-açúcar e do resíduo em contato com o solo, Bezerra
\& Cantalice (2006) observaram maiores taxas de infiltração de água no solo e menores taxas da erosão em entressulcos no tratamento com o resíduo da cana em contato direto com o solo, que aumentou a rugosidade hidráulica, e o dossel pela ação de interceptação da chuva, que retardou o início do escoamento superficial.

A quantificação da erosão hídrica com o conhecimento dos processos físicos a ela atrelados é de fundamental importância na elaboração de medidas que visam maximizar o uso dos recursos hídricos disponíveis e para evitar os efeitos negativos decorrentes da produção, transporte e deposição de sedimentos (Paiva et al., 2001).

Dessa forma, este trabalho teve o objetivo de avaliar a proteção ambiental promovida pela cobertura vegetal da Caatinga, do feijão-guandu e da batata-doce em relação ao solo descoberto, por meio das taxas da erosão em entressulcos e das características hidráulicas do escoamento superficial vinculado à erosão em entressulcos, em um Luvissolo do alto sertão do PajeúPE.

\section{MATERIAL E MÉTODOS}

O estudo foi realizado no campus do Centro de Treinamento e Pesquisa em Pequena Irrigação CTPPI da UFRPE no município de Serra Talhada$\mathrm{PE}$, em uma área de cultivo de vazante a montante do açude Saco, inserida na região semi-árida do Alto Sertão do Rio Pajeú, a uma altitude de $429 \mathrm{~m}$ acima do nível do mar, nas coordenadas geográficas de $7^{\circ} 56$ ' 15 " de latitude sul e $38^{\circ} 18$ ' 45 " de longitude oeste, distando $420 \mathrm{~km}$ de Recife. De acordo com a classificação de Köppen, o clima enquadra-se no tipo Bwh, denominado semi-árido, quente e seco, com chuvas de verão-outono com pluviosidade média anual para o período de 1912 a 1991 de $647 \mathrm{~mm}_{\text {ano- }}{ }^{-1}$ (SUDENE, 1990) e temperatura média anual superior a $25{ }^{\circ} \mathrm{C}$.

A área experimental situou-se no terço médio de uma encosta de relevo ondulado cultivada anualmente com culturas de vazante, com $0,096 \mathrm{~m} \mathrm{~m}^{-1}$ de declive. O solo, segundo o Sistema Brasileiro de Classificação de Solos (Embrapa, 1999), é um Luvissolo Crômico órtico típico com horizonte A fraco textura arenosa fase Caatinga hiperxerófila. Os tratamentos consistiram das seguintes condições de solo proporcionadas na presença e na ausência de coberturas vegetais: (1) solo descoberto, sem vegetação e sem preparo, tendo ocorrido a retirada manual da vegetação que estava nascendo na área, evitando-se o revolvimento do solo; (2) cultura do guandu (Cajanus cajan) no espaçamento de 1,50 m entre linhas e 0,50 m entre plantas, semeado em pequenas covas feitas na superfície do solo, após o revolvimento do solo com enxada manual - cem dias após o plantio, foram aplicados os testes com chuva simulada, período em 
que as plantas estavam no estádio fenológico de floração e formação de vagens e apresentavam cobertura vegetal uniforme; (3) cultura da batata-doce (Ipomoea batatas Lam) cultivada no espaçamento de $0,50 \mathrm{~m}$ entre leiras e $0,25 \mathrm{~m}$ entre plantas na mesma leira - também aos 100 dias após o plantio, foram realizadas as chuvas simuladas, época em que as plantas estavam alcançando o máximo crescimento vegetativo; e (4) Caatinga semi-arbustiva com predominância de plantas de pequeno porte com até $2 \mathrm{~m}$ de altura e localizada junto à área de vazante. Foram testados quatro tratamentos com cinco repetições, totalizando 20 parcelas experimentais. De cada tratamento foram coletadas antes da realização dos testes cinco amostras de solo na profundidade de 0 a $20 \mathrm{~cm}$, as quais foram acondicionadas em sacos plásticos e posteriormente secas ao ar, destorroadas e passadas em peneiras com malha de $2 \mathrm{~mm}$, para determinação da distribuição granulométrica pelo método do densímetro e da densidade de partícula $\mathrm{D}_{\mathrm{p}}$, pelo método do balão volumétrico (Embrapa, 1997). A densidade do solo $\mathrm{D}_{\mathrm{s}}$ foi determinada pelo método do cilindro (Klute, 1986). A porosidade total foi estimada.

Ainda, em cada tratamento foram coletadas amostras de solo e acondicionadas em latas de alumínio, que foram vedadas para determinação da umidade inicial (Quadro 1).

O plantio das culturas de guandu e batata-doce no sistema de cultivo de sequeiro ocorreu na primeira semana de janeiro de 2005 , junto a uma área de Caatinga semi-arbustiva. O experimento foi realizado no mês de abril de 2005 (final da época de chuvas na região), consistindo de uma série de 20 eventos de chuva com duração de $80 \mathrm{~min}$, gerados por meio de um simulador de chuvas desenvolvido no Laboratório de Conservação do Solo do Departamento de Agronomia da Universidade Federal Rural de Pernambuco, equipado com um bico aspersor tipo Veejet 80-150 com diâmetro interno de $12,7 \mathrm{~mm}$, fabricado pela Spraying System Company. Os bicos aspersores Veejet 80-100 e 80-150 da Spraying System foram utilizados nos simuladores em entressulcos
(Meyer \& Harmon, 1979), por reproduzirem uma distribuição de tamanho de gotas e níveis de energia cinética próxima às das chuvas naturais. Após o simulador ser instalado, o bico fica a $3,1 \mathrm{~m}$ acima da superfície do solo e opera a uma pressão de serviço constante de $41 \mathrm{kPa}$ na extremidade de saída da água no bico, verificada com o auxílio de um manômetro. O simulador de chuva foi abastecido por uma bomba submersa colocada em um reservatório de água de $1.000 \mathrm{~L}$. Com base nas chuvas locais mais intensas com 50 anos de período de retorno, a partir de Molinier et al. (1994), que utilizaram o método do vetor regional, a intensidade de chuva programada foi de $140 \mathrm{~mm} \mathrm{~h}^{-1}$. A intensidade média das chuvas geradas $\left(147 \mathrm{~mm} \mathrm{~h}^{-1}\right)$ foi aferida por meio de um conjunto de 10 pluviômetros instalados ao acaso dentro e ao lado da área útil das parcelas experimentais.

As parcelas experimentais, delimitadas por chapas metálicas galvanizadas de $30 \mathrm{~cm}$ de altura, cravadas no solo a $20 \mathrm{~cm}$ de profundidade, possuíam área útil de $2 \mathrm{~m}^{2}$ ( $1 \mathrm{~m}$ de largura e $2 \mathrm{~m}$ de comprimento), ficando a maior dimensão no sentido do declive. Elas continham, na parte inferior, uma calha coletora para amostragem do escoamento superficial.

A percentagem de cobertura do solo promovida pelas diferentes coberturas vegetais foi determinada pelo método de Mannering descrito por Bezerra et al. (2002), que utiliza a projeção fotográfica de um quadro da cobertura vegetal com as dimensões de $76 \times 51 \mathrm{~cm}$, numa moldura-padrão com $38 \mathrm{~cm}$ de comprimento e $25,4 \mathrm{~cm}$ de largura. Essa moldura contém 50 pontos de interseção de linhas verticais com linhas horizontais, onde cada coincidência dos pontos de interseção das linhas (verticais e horizontais) com a projeção de qualquer cobertura vegetal corresponde a $2 \%$ de cobertura de solo pela vegetação. $\mathrm{O}$ somatório dos pontos de interseção corresponde à área total de solo coberta pela vegetação, em $\mathrm{m}^{2} \mathrm{~m}^{-2}$.

A descarga líquida (q) por unidade de largura foi determinada a partir das coletas da mistura de água e sedimento em potes plásticos com capacidade de $1 \mathrm{~L}$ na extremidade da calha coletora, com duração de $10 \mathrm{~s}$

Quadro 1. Porosidade total (Pt), densidade do solo (Ds), densidade de partículas (Dp), distribuição granulométrica e umidade inicial de um Luvissolo sob diferentes coberturas, na região semi-árida do sertão do alto Pajeú-PE

\begin{tabular}{|c|c|c|c|c|c|c|c|}
\hline \multirow{2}{*}{$\begin{array}{c}\text { Cobertura } \\
\text { vegetal }\end{array}$} & \multirow[b]{2}{*}{$\mathbf{P t}$} & \multirow[b]{2}{*}{$\mathbf{D}_{\mathrm{s}}$} & \multirow[b]{2}{*}{$\mathbf{D}_{\mathrm{p}}$} & \multicolumn{3}{|c|}{ Distribuição granulométrica } & \multirow{2}{*}{$\begin{array}{l}\text { Umidade } \\
\text { inicial }\end{array}$} \\
\hline & & & & Areia & Silte & Argila & \\
\hline & $\mathrm{cm}^{3} \mathrm{~cm}^{-3}$ & $\mathrm{~kg} \mathrm{dm}^{-3}$ & - & 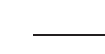 & $\mathrm{g} \mathrm{kg}^{-1}$ & - & $\mathrm{cm}^{3} \mathrm{~cm}^{-3}$ \\
\hline Guandu & 0,38 & 1,58 & 2,58 & 801 & 120 & 79 & 0,04 \\
\hline Caatinga & 0,43 & 1,46 & 2,56 & 825 & 86 & 89 & 0,07 \\
\hline Batata & 0,44 & 1,43 & 2,56 & 750 & 164 & 86 & 0,08 \\
\hline Descoberto & 0,37 & 1,65 & 2,63 & 812 & 97 & 91 & 1,00 \\
\hline
\end{tabular}


a cada 5 min. A velocidade superficial $\left(\mathrm{V}_{\mathrm{S}}\right)$ do escoamento gerado a partir da chuva simulada foi determinada pela tomada de tempo gasto, por meio de um cronômetro, para o corante (azul de metileno) percorrer a distância entre dois pontos fixos na parcela. Essas determinações foram realizadas em intervalos de 5 min, a partir da formação e de deslocamento da lâmina de escoamento. As velocidades médias do escoamento (V) foram determinadas pelo produto das velocidades superficiais do escoamento pelo fator de correção ( $\alpha=2 / 3)$, conforme Farenhorst \& Bryan (1995), Katz et al. (1995) e Bezerra \& Cantalice (2006). O coeficiente de escoamento superficial (C) foi determinado pela relação do volume escoado superficialmente pelo volume precipitado, obtido em cada tratamento.

A altura da lâmina do escoamento h foi obtida pela equação (1), derivada por Woolhiser \& Liggett (1967) e Singh (1983) para fluxo em um plano sob chuva de duração finita e já utilizada por Cassol et al. (2004) e Bezerra \& Cantalice (2006):

$$
h=\frac{q}{V}
$$

em que $\mathrm{h}=$ altura da lâmina de escoamento $(\mathrm{m}) ; \mathrm{q}=$ descarga líquida por unidade de largura $\left(\mathrm{m}^{2} \mathrm{~s}^{-1}\right) ; \mathrm{eV}$ $=$ velocidade média do escoamento $\left(\mathrm{m} \mathrm{s}^{-1}\right)$. O número de Reynolds (Re) foi obtido pela equação (2), segundo Simons \& Senturk (1992):

$$
R_{e}=\frac{V h}{v}
$$

em que $\mathrm{Re}=$ número de Reynolds, adimensional; $\mathrm{h}=$ altura da lâmina de escoamento $(\mathrm{m})$; e $v=$ viscosidade cinemática da água $\left(\mathrm{m}^{2} \mathrm{~s}^{-1}\right)$. A viscosidade cinemática (v) foi determinada pela utilização da equação (3), segundo Julien (1995), sendo a temperatura $\left({ }^{\circ} \mathrm{C}\right)$ aferida por meio de um termômetro em cada teste.

$$
V=\left[1,14-0,031(\mathrm{~T}-15)+0,00068(\mathrm{~T}-15)^{2}\right] \times 10^{-6}(3)
$$

em que $v=$ viscosidade cinemática da água $\left(\mathrm{m}^{2} \mathrm{~s}^{-1}\right) \mathrm{e}$ $\mathrm{T}=$ temperatura da água $\mathrm{em}^{\circ} \mathrm{C}$. O número de Froude (Fr) foi obtido pela equação (4), de acordo com Simons \& Senturk (1992):

$$
F_{r}=\frac{V}{\sqrt{g h}}
$$

em que $\mathrm{Fr}=$ número de Froude, adimensional; $\mathrm{h}=$ altura da lâmina de escoamento (m); e g = aceleração da gravidade $\left(\mathrm{m} \mathrm{s}^{-2}\right)$. A partir dos números de Reynolds e Froude, obtiveram-se os regimes de escoamento gerados a partir das chuvas simuladas. Determinou-se também a resistência ao escoamento em regime laminar pela equação do coeficiente de rugosidade de Darcy-Weisbach (f), que define a perda de carga do escoamento (Gerits et al., 1990) e é dada pela equação (5):

$$
f=\frac{8 g h S}{V^{2}}
$$

em que $f=$ adimensional e expresso na forma logarítmica; $\mathrm{S}=$ inclinação do declive $\left(\mathrm{m} \mathrm{m}^{-1}\right) ; \mathrm{g}=$ aceleração da gravidade $\left(\mathrm{m} \mathrm{s}^{-2}\right) ; \mathrm{h}=$ altura da lâmina do escoamento $(\mathrm{m})$; e $\mathrm{V}=$ velocidade média do escoamento $\left(\mathrm{m} \mathrm{s}^{-1}\right)$.

As taxas de perdas de solo e a concentração de sedimentos foram determinadas pela pesagem do material coletado nos potes plásticos. Aos potes, após a pesagem, adicionaram-se $5 \mathrm{~mL}$ de sulfato de $\mathrm{Al}$ dodecaidratado (alúmen de K) a $5 \%$, para deposição das partículas (Cantalice, 2002). Vinte e quatro horas depois, o sobrenadante foi succionado e os potes levados para secagem em estufa a $65^{\circ} \mathrm{C}$, sendo posteriormente pesados com o solo. A relação entre a massa de solo seco e a massa de mistura água-sedimento expressa a concentração de sedimentos em $\mathrm{kg} \mathrm{L}^{-1}$.

As taxas de desagregação do solo em entressulcos $\left(\mathrm{D}_{\mathrm{e}}\right)$ foram determinadas conforme a expressão a seguir:

$$
D_{e}=\frac{M_{S S}}{A \cdot D_{c}}
$$

em que $D_{e}=$ taxa de desagregação do solo em entressulcos $\left(\mathrm{kg} \mathrm{m}^{-2} \mathrm{~s}^{-1}\right) ; \mathrm{M}_{\mathrm{ss}}=$ massa do solo seco desagregado (kg); $\mathrm{A}=$ área da parcela $\left(\mathrm{m}^{2}\right)$; e $\mathrm{D}_{\mathrm{c}}=$ duração da coleta em (s).

As perdas de solo (Ps) foram estimadas pela seguinte equação:

$$
P s=\frac{\sum(Q \cdot C s \cdot t)}{A}
$$

em que $\mathrm{Ps}_{\mathrm{s}}=$ perdas de solo $\left(\mathrm{kg} \mathrm{m}^{-2}\right) ; \mathrm{Q}=\operatorname{vazão}\left(\mathrm{L} \mathrm{s}^{-1}\right)$; $\mathrm{Cs}_{\mathrm{s}}=$ concentração de sedimentos $\left(\mathrm{kg} \mathrm{L}^{-1}\right) ; \mathrm{e} \mathrm{t}=$ intervalo entre as coletas (300 s).

O delineamento experimental utilizado foi o inteiramente casualizado, sendo os resultados submetidos à análise de variância (teste F a $5 \%$ ), regressões e teste de Duncan para comparação das médias, por meio do programa estatístico SAS Statistical Analitical System (SAS, 1998).

\section{RESULTADOS E DISCUSSÃO}

No quadro 2 encontram-se as condições hidráulicas médias dos escoamentos superficiais obtidos nas diferentes condições de cobertura vegetal no Luvissolo do semi-árido do Alto Sertão do Rio Pajeú, com a lâmina estabilizada a partir dos 50 min de teste. Observa-se que a Caatinga apresentou as menores taxas de descarga líquida (q), seguida do guandu e da batata-doce. 
A atuação desta última deve-se ao fato de o sistema de cultivo em leiras reter o escoamento superficial. A maior retenção da descarga líquida pela Caatinga justifica-se pela maior resistência físico-hidráulica ao escoamento criada pela sua copa e camada de serrapilheira, traduzida no maior valor do coeficiente de rugosidade hidráulica $f$ de Darcy-Weisbach.

As maiores alturas de lâmina de escoamento superficial (h) foram observadas para os escoamentos sobre as coberturas vegetais da Caatinga e do guandu (Quadro 2) e podem ser atribuídas às sobre-elevações das lâminas causadas pelas maiores quantidades de resíduos na superfície do solo, como atestam os maiores valores de cobertura do solo CS (Quadro 3) e os de rugosidade hidráulica ( $f$ ). Da mesma forma, os maiores valores de rugosidade hidráulica ao escoamento produzido sobre as culturas do guandu e da Caatinga determinaram reduções nas respectivas velocidades médias de escoamento, como também observado por Cassol et al. (2004) e Pruski et al. (1997), na presença de resíduos vegetais.

Por conseqüência da interação da lâmina de escoamento rasa com os efeitos viscosos aumentados pelas coberturas vegetais, os valores de número de Reynolds para todas as condições de cobertura de superfície, entre 41,3 para a caatinga e 106,2 para o solo descoberto, juntamente com os valores do número de Froude entre 0,19 e 0,91, conferem a todos os escoamentos gerados o regime de escoamento laminar lento (Simons \& Senturk, 1992), característico da erosão em entressulcos, estando em concordância com os escoamentos obtidos com chuva simulada por Guy et al. (1990), Farenhorst \& Bryan (1995), Cantalice (2002), Bezerra et al. (2002), Cassol et al. (2004) e Bezerra \& Cantalice (2006).

A relação dos valores de rugosidade (f) com os valores dos números de Reynolds obtidos em todos os escoamentos gerados pela chuva simulada no experimento (Figura 1), indicam aumento das forças de viscosidade (valores do coeficiente de rugosidade $f$ ) originados pelas maiores quantidades de resíduos vegetais oriundos da cobertura vegetal, resultando em maior cobertura do solo, determinantes na redução dos valores de Reynolds. A magnitude das médias de rugosidade para os valores de Reynolds obtidos nas condições de escoamento do semi-árido pernambucano está em concordância com os valores de Gerits et al. (1990) para as condições de chuva simulada, sendo semelhantes à mesma relação obtida por Wainwright (1996) em duas áreas cultivadas com a videira.

Quadro 2. Características hidráulicas do escoamento gerado por chuva simulada sobre diferentes coberturas vegetais estudadas na região semi-árida de Pernambuco

\begin{tabular}{lcccc}
\hline & Caatinga semi-arbustiva & Guandu & Batata-doce & Solo descoberto \\
\hline$q\left(\mathrm{~m}^{2} \mathrm{~s}^{-1}\right)$ & $2,468 \times 10^{-5} \mathrm{c}$ & $6,547 \times 10^{-5} \mathrm{c}$ & $6,892 \times 10^{-5} \mathrm{~b}$ & $9,373 \times 10^{-5} \mathrm{a}$ \\
$\mathrm{h}(\mathrm{mm})$ & $1,598 \mathrm{a}$ & $1,752 \mathrm{a}$ & $1,046 \mathrm{~b}$ & $1,026 \mathrm{~b}$ \\
$\mathrm{~V}\left(\mathrm{~m} \mathrm{~s}^{-1}\right)$ & $0,023 \mathrm{c}$ & $0,037 \mathrm{c}$ & $0,068 \mathrm{~b}$ & $0,091 \mathrm{a}$ \\
$\operatorname{Re}(\mathrm{ad})$ & $41,312 \mathrm{c}$ & $54,578 \mathrm{c}$ & $75,512 \mathrm{~b}$ & $106,232 \mathrm{a}$ \\
$\mathrm{Fr}(\mathrm{ad})$ & $0,195 \mathrm{c}$ & $0,303 \mathrm{c}$ & $0,6964 \mathrm{~b}$ & $0,918 \mathrm{a}$ \\
$\log f$ & $1,311 \mathrm{a}$ & $0,9779 \mathrm{~b}$ & $0,1428 \mathrm{c}$ & $0,0193 \mathrm{c}$
\end{tabular}

Médias seguidas de mesma letra não diferem entre si pelo teste de Duncan a $5 \%$. q: descarga líquida por unidade de largura; h: altura da lâmina de escoamento superficial; V: velocidade média do escoamento superficial; Re: número de Reynolds; Fr: número de Froude; f: coeficiente de rugosidade de Darcy-Weisbach. Média de cinco repetições.

Quadro 3. Variáveis da erosão em entressulcos e de resistência de um ambiente semi-árido ao processo erosivo

\begin{tabular}{|c|c|c|c|c|c|}
\hline Tratamento & Cs & $\mathbf{D}_{\mathrm{e}}$ & PS & C & CS \\
\hline & $\mathrm{kg} \mathrm{L}^{-1}$ & $\mathrm{~kg} \mathrm{~m}^{-2} \mathrm{~s}^{-1}$ & $\mathrm{Mg} \mathrm{ha}^{-1}$ & Adim. & $\mathrm{m}^{2} \mathrm{~m}^{-2}$ \\
\hline Caatinga semi-arbustiva & $0,0069 \mathrm{~b}$ & $2,21 \times 10^{-5} \mathrm{c}$ & $1,1919 \mathrm{~b}$ & $0,3230 \mathrm{c}$ & $0,8900 \mathrm{a}$ \\
\hline Guandu & $0,0031 \mathrm{~b}$ & $4,47 \times 10^{-5} \mathrm{c}$ & $1,7402 \mathrm{~b}$ & $0,5106 \mathrm{~b}$ & $0,7960 \mathrm{~b}$ \\
\hline Batata-doce & $0,0768 \mathrm{a}$ & $5,76 \times 10^{-4} \mathrm{~b}$ & $13,2820 \mathrm{~b}$ & $0,5460 \mathrm{~b}$ & $0,4400 \mathrm{c}$ \\
\hline Solo descoberto & $0,0261 \mathrm{a}$ & $1,23 \times 10^{-3} \mathrm{a}$ & $52,9283 \mathrm{a}$ & $0,9603 \mathrm{a}$ & $0,0000 \mathrm{~d}$ \\
\hline
\end{tabular}

Concentração de sedimentos (Cs), taxa de desagregação do solo em entressulcos (D $)$, perdas de solo (PS), coeficiente de escoamento superficial (C) e cobertura do solo (CS). Média de cinco repetições. 
No quadro 3 têm-se as variáveis de erosão (concentração de sedimentos, perdas de solo, coeficiente de escoamento superficial e taxas de desagregação do solo em entressulcos) e as cobertura do solo, representando as variáveis de resistência da vegetação e do solo envolvidas no processo erosivo, originando a rugosidade hidráulica (Quadro 2). Em relação à concentração de sedimentos, observa-se que os tratamentos com cobertura vegetal de Caatinga e guandu apresentaram valores de concentração de sedimentos inferiores ao do solo descoberto e da batatadoce, o que se justifica pelas maiores coberturas vegetais proporcionadas e conseqüente resistência ao escoamento traduzida na forma de rugosidade hidráulica (f), obtidas na vegetação de Caatinga e guandu. Embora a cultura da batata-doce tenha apresentado uma fração de 0,44 de cobertura de solo (Quadro 3), sua taxa de concentração de sedimentos igualou-se à de sedimentos do solo descoberto. Isso se deu em razão da maior mobilização do solo durante as operações de preparo, já que o cultivo da batata foi realizado no sistema de leiras, o que levou ao revolvimento da superfície do solo, ficando este mais exposto ao contato direto das gotas de chuva que acontecem na erosão em entressulcos. Pode também ser devido ao fato de o sistema radicular da batata ser formado por raízes superficiais, que se concentram nos primeiros $10 \mathrm{~cm}$ de profundidade (Filgueira, 1982). Valores de concentração de sedimentos semelhantes aos da área com solo descoberto e batata-doce $\left(0,012 \mathrm{~kg} \mathrm{~L}^{-1}\right)$ foram encontrados por Lasanta et al. (2000) numa área de cultivo abandonada no semi-árido da Espanha e também sob chuva simulada de alta intensidade $\left(100 \mathrm{~mm} \mathrm{~h}^{-1}\right)$.

As perdas de solo para os tratamentos de Caatinga, guandu e batata-doce só se diferenciaram das perdas obtidas com o solo descoberto. Apesar de as perdas de solo da batata-doce serem estatisticamente iguais às

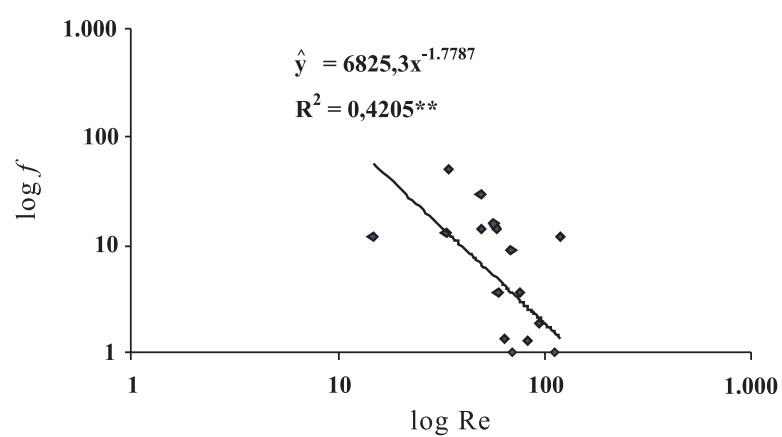

Figura 1. Relação entre os valores de rugosidade hidráulica (coeficiente de Darcy-Weiscbach $f$ ) e números de Reynolds dos escoamentos gerados por chuva simulada, obtidos em um Luvissolo na presença das diferentes coberturas vegetais na região semi-árida do sertão do alto Pajeú: caatinga, guandu e batata-doce, e solo descoberto. Significância de $5 \%$, média de cinco repetições e total de eventos $(n)=20$. perdas da Caatinga e do guandu, seu valor refletiu a menor cobertura vegetal e resistência criadas por ela, em relação às coberturas de solo originadas da caatinga e do guandu. $\mathrm{Na}$ área com vegetação de Caatinga onde se manteve a estrutura do solo intacta, sem revolvimento, o solo apresentou melhor agregação. $\mathrm{O}$ mesmo pode ocorrer na área com o guandu, o qual apresenta sistema radicular profundo (Alvarenga et al., 1995), com raiz pivotante, que normalmente atinge até $1 \mathrm{~m}$, e numerosas raízes secundárias, que atingem até $30 \mathrm{~cm}$ de profundidade, e isso pode ter contribuído para o desenvolvimento de um melhor estado de agregação da estrutura do solo.

As taxas de desagregação do solo, cuja avaliação é instantânea, diferentemente das perdas de solo, que consistem em um somatório, apontam as coberturas proporcionadas pela caatinga e guandu como as mais conservativas, refletindo a resistência hidráulica ao escoamento ( $f$ ) criada por estas, que, segundo Pruski et al. (1997), ocorre pela interceptação promovida pela vegetação, que amortece a energia do impacto das gotas de chuva e reduz a desagregação do solo. A ordem de grandeza entre $10^{-3}$ e $10^{-5}$ das taxas de desagregação do solo, juntamente com o regime de escoamento laminar lento (Quadro 2), atesta a ocorrência da erosão em entressulcos em todos os tratamentos.

Em relação à descarga líquida e, conseqüentemente, ao coeficiente de escoamento superficial, todos os tratamentos com cobertura vegetal diferenciaram-se do solo descoberto, tendo a caatinga apresentado o menor valor $(0,32)$. A vegetação de Caatinga foi mais eficiente no controle da descarga líquida, pelo fato de o solo sob essa vegetação não sofrer preparo e, também, pela sua maior cobertura de solo (CS), que se traduziu em maior rugosidade hidráulica $(f)$ à ação da chuva e do escoamento superficial. O valor de descarga líquida ocorrida no cultivo da batata-doce foi igual ao do feijãoguandu, apesar da sua menor cobertura de solo (Quadro 2). Isso aconteceu pela construção das leiras no cultivo da batata-doce, que se constituiu numa barreira física ao livre escoamento superficial. O efeito de retenção do escoamento superficial pelas leiras de plantio da batata-doce é confirmado pelo seu baixo valor de rugosidade hidráulica, em relação à vegetação de Caatinga e do feijão-guandu, já que a rugosidade hidráulica seria a outra maneira de retenção do escoamento superficial.

Na figura 2 é apresentada a redução das perdas de solo causadas pela erosão em entressulcos com o aumento exponencial da rugosidade hidráulica, originada pela passagem da condição do Luvissolo descoberto no semi-árido para as condições promovidas pelo cultivo da batata-doce e do guandu e pela vegetação da Caatinga semi-arbustiva, estimadas pela seguinte expressão, obtida a partir dos 20 eventos de chuva:

$$
\mathrm{PS}=1,7233 \log f^{-0,9048} \mathrm{R}^{2}=0,99^{* * *}
$$

em que $\mathrm{PS}=$ perdas de solo em $\mathrm{Mg} \mathrm{ha}^{-1}$ e $f=$ coeficiente de rugosidade hidráulica de Darcy-Weisbach. 


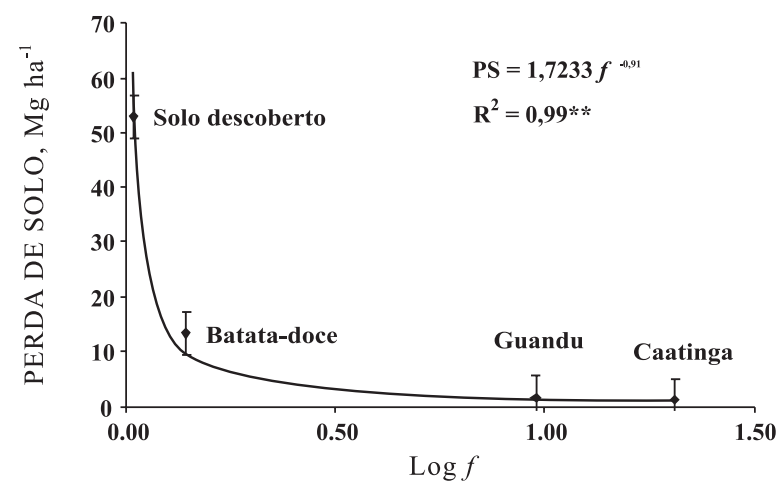

Figura 2. Redução das perdas de solo (PS) na erosão em entressulcos, em função do coeficiente de rugosidade hidráulica de Darcy-Weisbach $(f)$, originadas pelas diferentes coberturas vegetais em um Luvissolo da região semi-árida do sertão do alto Pajeú: caatinga, guandu e batata-doce e solo descoberto. Significância de $5 \%$, média de cinco repetições e total de eventos $(n)=20$.

Como a vegetação de Caatinga semi-arbustiva e a do feijão-guandu apresentaram altura de dossel em torno de 1,5 m, pode-se dizer que o escoamento de água pelos seus troncos, caules e galhos, conhecido como fluxo de caule, originado a partir da interceptação vegetal da chuva pelo dossel da Caatinga e do feijãoguandu, mobilizou volumes de água por algum tempo, que, assim, não chegaram rapidamente ao solo e contribuíram para o retardamento do escoamento superficial.

\section{CONCLUSÕES}

1. Todos os regimes de escoamento superficial obtidos foram laminar lento, e as coberturas de Caatinga e guandu determinaram as maiores reduções de velocidade média dos respectivos escoamentos superficiais.

2. O efeito benéfico da cobertura vegetal foi comprovado em relação à retenção dos volumes de escoamento superficial, em razão do aumento das forças viscosas, que se contrapõem ao livre escoamento superficial.

3. As coberturas vegetais proporcionadas pela $\mathrm{Ca}$ atinga semi-arbustiva e pelo guandu apresentaram os maiores valores de cobertura do solo e responderam pelos menores valores da concentração de sedimentos e da taxa de desagregação do solo na erosão em entressulcos.

4. O revolvimento do solo na preparação das leiras para o plantio da batata-doce igualou as taxas de concentração de sedimentos às mesmas obtidas para o solo descoberto e determinou as maiores taxas de desagregação do solo entre todas as coberturas vegetais; em contrapartida, as leiras permitiram retenção do escoamento superficial.
5. Na cobertura vegetal da Caatinga semi-arbustiva observou-se o menor coeficiente de escoamento superficial.

\section{LITERATURA CITADA}

ALVARENGA, R.C.; COSTA, L.M.; MOURA FILHO, W. \& REGAZZI, A.J. Características de alguns adubos verdes de interesse para a conservação e recuperação de solos. Pesq. Agropec. Bras., 30:175-185, 1995.

ALVES, S.J. \& MEDEIROS, G.B. Leguminosas em renovação de pastagens. In: FAVORETTO, V.; RODRIGUES, L.R.A. \& RODRIGUES, T.J.D., eds. SIMPÓSIO SOBRE ECOSSISTEMAS DE PASTAGENS, 3., Jaboticabal, 1997. Anais. FUNEP, 1997. p.251-272.

BEZERRA, S.A. \& CANTALICE, J.R.B. Erosão entre sulcos em diferentes condições de cobertura do solo sob cultivo da cana-de-açúcar R. Bras. Ci. Solo, 30:565-573, 2006.

BEZERRA, S.A.; CANTALICE, J.R.B. \& TARQUI, J.L.Z. Características do escoamento superficial e taxas de erosão em uma área sob cultivo agrícola. In: ENCONTRO NACIONAL DE ENGENHARIA DE SEDIMENTOS, 5; São Paulo, 2002. Anais. São Paulo, ABRH, 2002. p.403411.

CANTALICE, J.R.B. Escoamento e erosão em sulcos e em em entressulcos em distintas condições de superfície do solo. Porto alegre, Universidade Federal do Rio Grande do Sul, 2002. 141p. (Tese de Doutorado)

CASSOL, E.A.; CANTALICE, J.R.B.; REICHERT, J.M. \& MONDARDO, A. Escoamento superficial e desagregação do solo em em entressulcos em solo franco-argilo-arenoso com resíduos vegetais. Pesq. Agropec. Bras., 39:685-690, 2004.

EMPRESA BRASILEIRA DE PESQUISA AGROPECUÁRIA EMBRAPA. Manual de métodos de análise do solo. Rio de Janeiro, 1997. 212p.

EMPRESA BRASILEIRA DE PESQUISA AGROPECUÁRIA EMBRAPA. Sistema brasileiro de classificação de solos. Brasília, 1999. 412p.

EVERAERT, W. Empirical relations for the sediment transport capacity of interrill flow. Earth Surf. Landf., 16:513-532, 1991.

FARENHORST, A. \& BRYAN, R.B. Particle size distribution of sediment transported by shallow flow. Catena, 25:4762, 1995.

FILGUEIRA, F.A. Manual de olericultura. Cultura e comercialização de hortaliças. São Paulo, Ceres, 1982. v.2. $357 \mathrm{p}$.

GERITS, J.J.P.; LIMA, J.L.P.D. \& BROEK, T.M.W.V.D. Overland flow and erosion. In: ANDERSON, M.G. \& BURT, T.P., eds. Process studies in hill slope hydrology. Chichester, Jonh Wiley \& Sons, 1990. p.173-214

GUY, B.T.; DICKINSON, W.T. \& RUDRA, R.P. Hydraulics of sediment-landen sheet flow and the influence of simulated rainfall. Earth Surf. Landf., 15:101-118, 1990. 
HERNANI, L.C.; KURIHARA, C.H. \& SILVA, W.M. Sistemas de manejo de solo e perdas de nutrientes e matéria orgânica por erosão. R. Bras. Ci. Solo, 23:145-154, 1999.

JULIEN, P.Y. Erosion and sedimentation. Melbourne, Cambridge University Press, 1995. 280p.

KATZ, D.M.; WATTS, F.J. \& BURROUGHS, E.R. Effects of surface roughness and rainfall impact on overland flow. J. Hydr. Division, ASCE, 121:547-553, 1995.

KLUTE, A. Methods of soil analysis, part 1, physical and mineralogical methods. 2.ed. Soil, Madison, Sci. Soc. Amer., 1986. 1188p.

LAL, R. Methods and guidelines for assessing sustainable use of soil and water resources in the tropics. Soil Management Support Services-USDA, n. 21. 1994. 78p.

LASANTA, T.; GARCÍA-RUIZ, J.M.; PÉREZ-RONTOMÉ, C. \& SANCHO-MARCÉN, C. Runoff and sediment yield in a semiarid environment: The effect of land management after farmland abandonment. Catena, 38:265-278. 2000.

MIRANDA, J.E.C.; FRANÇA, F.H.; CARRIJO, O.A; SOUZA, A.F.; PEREIRA, W.; LOPES, C.A. \& SILVA, J.B.C. A cultura da batata-doce. Brasília, EMBRAPA/Centro Nacional de Pesquisa de Hortaliças, 94 p.1995. (Coleção Plantar, 30)

MEYER, L.D. \& HARMON, W.C. Multiple intensity rainfall simulator for erosion research on row sideslopes. Trans. ASAE, 22:100-103, 1979.

MOLINIER, M.; ALBUQUERQUE, C.H. \& CADIER, E. Análise da pluviometria e isoietas homogeneizadas do Nordeste brasileiro. Recife, SUDENE, 1994. 58p. (Série Hidrologia, 32)

PAIVA, E.M.C.D.; PAIVA, J.B.D.; MOREIRA, A.P; MAFFINI, G.F.; MELLER, A \& DILL, P.R.J. Evolução de processo erosivo acelerado em trecho do Arroio Vacacaí Mirim. R. Bras. Rec. Hídr., 6:129-135, 2001.
PRUSKI, F,F.; SILVA, D.D.; SANTOS, W.L.; RODRIGUES, L.N. \& ANTUNES, V.L. Infiltração de água no solo. ViçosaMG, Engenharia na Agricultura, 1997. 26p. (Caderno didático, 25)

RAO. S.C.; COLEMAN. S.W. \& MAYEUX, H.S. Forage production and nutritive value of selected pigeonpea ecotypes in the Southern Great Plains. Crop Sci., 42:12591263, 2002.

SAMPAIO, E.V.DE S.B.; ARAÚJO, E. DE L.; SALCEDO, I. \& TIESSEN, H. Regeneração da vegetação de Caatinga após corte e queima, em Serra Talhada-PE. Pesq. Agropec. Bras., 33:621-632, 1998.

SAS Institute, Inc. The SAS System for Windows: Releasa ver. 6.8, Cary, 1998. 1CD-ROM.

SILVA, V.F. Associações de características da batata-doce (Ipomoea batatas (L) Lamarck) com a sua resistência à "broca da raiz" Euscepes postfasciatus (Fairmaire). Viçosa, MG, Universidade Federal de Viçosa, 1991. 162p. (Tese de Doutorado)

SIMONS, D.B. \& SENTURK, F. Sediment transport technology: Water and sediment dynamics. Fot Collins, Water Resources Publications. 1992. 897p.

SINGH, V.P. Analytical solutions of cinematic for erosion on a plane: II Rainfall of finite duration. Adv. Water Res., 6:8895, 1983.

SUDENE - SUPERINTENDÊNCIA DE DESENVOLVIMENTO DO NORDESTE. Dados pluviométricos mensais do Nordeste: Estação de Pernambuco: Recife, 1990. 363p. (Série pluviométrica, ${ }^{\circ} 6$ )

WAINWRIGHT, J. Infiltration, runoff and erosion characteristics of agricultural land in extreme storms events, SE France. Catena, 26:27-47. 1996.

WOOLHISER. D.A. \& LIGGETT, J.A. Unsteady onedimensional flow over a plane - The rising hydrograph. Water Res. Res., 3:753-771, 1967. 